\title{
Reducing uncertainties in flood inundation outputs of a two-dimensional hydrodynamic model by constraining roughness
}

\author{
Punit Kumar Bhola, Jorge Leandro, and Markus Disse \\ Chair of Hydrology and River Basin Management, Department of Civil, Geo and Environmental Engineering, \\ Technical University of Munich, Arcisstrasse 21, 80333 Munich, Germany
}

Correspondence: Punit Kumar Bhola (punit.bhola@tum.de)

Received: 3 December 2018 - Discussion started: 5 February 2019

Revised: 18 May 2019 - Accepted: 9 June 2019 - Published: 18 July 2019

\begin{abstract}
The consideration of uncertainties in flood risk assessment has received increasing attention over the last 2 decades. However, the assessment is not reported in practice due to the lack of best practices and too wide uncertainty bounds. We present a method to constrain the model roughness based on measured water levels and reduce the uncertainty bounds of a two-dimensional hydrodynamic model. Results show that the maximum uncertainty in roughness generated an uncertainty bound in the water level of $1.26 \mathrm{~m}$ (90\% confidence interval) and by constraining roughness, the bounds can be reduced as much as $0.92 \mathrm{~m}$.
\end{abstract}

\section{Introduction}

Uncertainties in flood risk assessment have received increasing attention from researchers over the last 2 decades. In Germany, flood risk management plans rely on hydrodynamic (HD) models to determine the impact of flooding for areas of potential flood risk (Thieken et al., 2016). Two-dimensional (2-D) HD models are widely used to simulate flood hazards in the form of water depth, inundation extent, and flow velocity (Disse et al., 2018). The hazard maps depict inundated areas for floods above certain exceedance levels, which leads to an improvement in flood risk assessment through increased spatial planning and urban development (Hagemeier-Klose, 2007).

Even though HD models are physically deterministic, they contain numerous uncertainties in model outputs (Bates et al., 2014; Beven et al., 2018). Information about the type and magnitude of these uncertainties is crucial for decisionmaking and for increasing confidence in model predictions (Oubennaceur et al., 2018). Despite uncertainties, decisionmaking in practice is based on first-hand data, expert judgement, and/or a calibrated model output (Henonin et al., 2013; Uusitalo et al., 2015). Uncertainties associated with exceedance level scenarios are usually not quantified for at least five reasons: (1) most of the sources of uncertainty are not recognized (Bales and Wagner, 2009), (2) the data required to quantify uncertainty are seldom available (Werner et al., 2005a), (3) high computational resources are required to perform an extensive uncertainty assessment, (4) the wide uncertainty bounds cannot be incorporated into the decisionmaking process (Pappenberger and Beven, 2006), and (5) the uncertainty analysis is complex and is not considered for the final decision (Merwade et al., 2008).

The major sources of uncertainty in HD models can be categorized as model structure, model input, model parameters, and the modeller (Matott et al., 2009; Schumann et al., 2011). The model structure, essentially either 1-D, 2-D, or hybrid 1-D-2-D HD code, is generally selected based on the purpose and scale of the modelling (Musall et al., 2011; Bach et al., 2014). In addition, there is no general agreement on the best approach to consider model structure uncertainty; hence, it is often neglected (Oubennaceur et al., 2018). In the case of hindcasting a flood event based on measured discharges or water levels as the input boundary conditions and a fineresolution elevation, roughness remains the main source of uncertainty in HD models; hence we focus this study on roughness uncertainty. 
The precise meaning of roughness changes based on a model's physical properties, such as grid resolution and time step (Bates et al., 2014), and the term is denoted as Manning's roughness coefficient or simply Manning's $n$ in most HD models. Various studies point out that HD models can be very sensitive to Manning's $n$, which implies a higher degree of uncertainty (Aronica et al., 1998; Pappenberger et al., 2005; Werner et al., 2005a). The coefficient is either derived from measurements in the field or estimated from the relevant literature on the basis of land use types, but it has proven very difficult to demonstrate that such models can provide accurate predictions using only measured or estimated parameters (Hunter et al., 2007). In addition, Manning's $n$ is not only related to bottom friction but also includes incorrect representation of turbulence losses, 3-D effects, and incorrect geometry (profiles); therefore, it cannot be measured exactly. The spatial distribution of the Manning's $n$ in floodplains is challenging and depends on many factors, such as vegetation type, soil surface, and imperviousness (Sellin et al., 2013). Traditionally, this coefficient can be best estimated based on lookup tables of land use types (Werner et al., 2005b).

In order to understand views on uncertainty analysis, it is important to look at the different modeller types. According to Pappenberger and Beven (2006), there are different modeller types: physically based modellers believe that their models are physically accurate and that the roughness must not be adjusted under any circumstances, the second modeller type believes that the roughness should be calibrated within a strictly known range (Wagener and Gupta, 2005), and the third modeller type uses effective roughness beyond the accepted range (Pappenberger et al., 2005). The first modeller type would reject any calibration or uncertainty analysis; however, HD models make simplifying assumptions and do not consider all known processes that occur during a flood event (Romanowicz and Beven, 2003). Hence, models are subjected to a degree of structural errors that are typically compensated for by calibrating Manning's $n$ (Bates et al., 2014). However, effective roughness identified for one flood event might not hold true for another (Romanowicz and Beven, 2003), and a range of parameters should be defined where equifinality can be observed. Beven (2006) argued that the prior selected for the range of parameters should potentially cover all the accepted or behavioural models (modeller type 2 or 3). In HD models, selecting such a prior distribution for model parameter introduces the issue of too wide bounds.

Significant work has been carried out thus far in the quantification of HD model uncertainties and an overview of selected publications, including model roughness, is presented in Table 1. The major issue of wide uncertainty bounds raised by researchers and practitioners is reflected in the table. It shows the maximum bounds reported in each publication and in some cases these bounds are more than $50 \%$ of the available water depth (Aronica et al., 1998; Hall et al., 2005; Werner et al., 2005a; Jung and Merwade, 2012). This is indeed an issue but not a reason to ignore uncertainties in pre- dicting hazards. Moreover, decision makers must be made aware of potential risks associated with the possible outcomes of predictions, such as water levels and inundation extent (Pappenberger and Beven, 2006; Uusitalo et al., 2015).

The associated uncertainties can be constrained on measured data, if available, using a suitable goodness of fit or with the help of a sophisticated framework for assessment (Werner et al., 2005a). Few researchers have used frameworks, such as generalized likelihood uncertainty estimation (GLUE), the point estimate method, and global sensitivity analysis, to reduce the bounds. These methods, although widely used in research, are not employed in operational practice, and a straightforward approach is needed to reduce the bounds. Furthermore, there is a need to ensure efficiency in searching model parameter spaces for behavioural models (Beven, 2006).

This study investigates the use of measured water levels to reduce uncertainty bounds of HD model outputs. We begin with the approach of the third modeller type and select extreme ranges of model roughness in literature and gradually shift to the approach of the second modeller type by reducing the uncertainty bounds based on the measured data. The main focus of this paper is to constrain literature-based ranges of roughness using measured water levels and to assess uncertainties in water levels. Uncertainty is quantified for the flood event of January 2011 in the city of Kulmbach, Germany.

\section{Methods}

To investigate the effect of measured data on constraining parameters, an ensemble of parameter sets was sampled using a prior distribution. In the HD model, distributed roughness values were used based on land use and a single value was used for each land use class. The model domain was spatially discretized based on the classification of land use and parameter sets were sampled using a prior. The choice of the distribution influences the outcome; hence it should be selected carefully. The 2-D HD model was then run with each parameter set. The acceptance of each simulation was assessed by comparing the model outputs and measured data. The measured data can be static or time series water level measurements in the model domain and/or inundation extent gathered by field survey or post-event satellite images.

The performance of the simulations can be accessed using a suitable goodness of fit, such as Nash-Sutcliffe efficiency, the coefficient of determination, absolute error, etc., based on the purpose of application and measured data available. A behaviour threshold was applied to divide simulations with acceptable performances from those with unacceptable performances. Parameter sets that perform below the threshold were then selected at each location and an intersection at all the locations resulted in the final number of accepted simulations ( $r$ ) using Eq. (1):

$r=\bigcap_{i=1}^{n} P_{i}(\mathrm{GoF} \leq \mathrm{e})$, 
Table 1. A summary of selected publications including the maximum uncertainty bound reported. GLUE, PEM, GSA, and SD stand for generalized likelihood uncertainty estimation, point estimate method, global sensitivity analyses, and standard deviation respectively.

\begin{tabular}{lllllll}
\hline $\begin{array}{l}\text { Model } \\
\text { dimension }\end{array}$ & HD model & $\begin{array}{l}\text { Identified } \\
\text { sources }\end{array}$ & Method & $\begin{array}{l}\text { Sample } \\
\text { size }\end{array}$ & Max bound & Literature \\
\hline 1-D & HEC-RAS & Manning's $n$ & GLUE & 10000 & - & Pappenberger et al. (2005) \\
\hline 1-D & HEC-RAS & $\begin{array}{l}\text { Flow } \\
\text { Topography } \\
\text { Manning's } n\end{array}$ & GLUE & 5000 & $\sim 2.5 \mathrm{~m}(95 \%)$ in $8 \mathrm{~m}$ & Jung and Merwade (2012) \\
& & & & & \\
\hline 1-D-2-D & SOBEK & $\begin{array}{l}\text { Topography } \\
\text { Manning's } n\end{array}$ & GLUE & & $1.64 \mathrm{~m}(90 \%)$ in 1.51 m & Werner et al. (2005a) \\
\hline 2-D & & Manning's $n$ & GLUE & 1000 & $\sim 7 \mathrm{~m}(90 \%)$ in $10.5 \mathrm{~m}$ & Aronica et al. (1998) \\
\hline 2-D & H2-D2 & $\begin{array}{l}\text { Flow } \\
\text { Topography } \\
\text { Manning's } n\end{array}$ & PEM & 108 & $0.27 \mathrm{~m} \mathrm{SD} \mathrm{in} \mathrm{12.06} \mathrm{m}$ & Oubennaceur et al. (2018) \\
\hline 2-D & LISFLOOD-FP & $\begin{array}{l}\text { Flow } \\
\text { Topography } \\
\text { Manning's } n \\
\text { Channel width }\end{array}$ & GSA & 1792 & $6 \mathrm{~m} \mathrm{SD} \mathrm{in} 11 \mathrm{~m}$ & Hall et al. (2005) \\
& & & & & \\
\hline
\end{tabular}

where $n$ is the total number of observations, GoF is the goodness of fit used, $e$ is the threshold, and $P$ is the array of models that satisfy the criteria of GoF below the threshold.

\section{Materials}

\subsection{Study area and land use}

The city of Kulmbach is located in the north-east of the federal state of Bavaria in southern Germany. The city is categorized as a great district city with around 26000 inhabitants and a population density of 280 inhabitants per square kilometre in an area of $92.8 \mathrm{~km}^{2}$. The city is crossed by the river White Main and Mühl canal, which is a diversion canal for flood protection. Schorgast and Red Main are two main tributaries that meet the White Main upstream and downstream of the city respectively. In the north, the small tributary Dobrach meets the White Main and from the south side two storm water canals join the Mühl canal (see Fig. 1a). The main gauging stations upstream of the city are Ködnitz at White Main and Kauerndorf located at the river Schorgast.

The land use is shown in Fig. 1a and it generally consists of agricultural land $(62 \%)$ that includes floodplains and grassland. The water bodies make up $7 \%$ of the total model area and include rivers, canals, and lakes. The urban area covers around $26 \%$ of the land and includes industrial and residential areas as well as transport infrastructures like roads and railway tracks, whereas forests form barely $5 \%$ of the total area. Figure 2 shows images of the main channel and flood plain of the river White Main near site 1 .

\subsection{Measured discharges and water levels}

Hydrological measurement data for the winter flood event of January 2011 were collected by the Bavarian Hydrological Services. Figure 3 shows the discharge at the main two gauges upstream of the city, Ködnitz and Kauerndorf. Intense rainfall and snow melting in the Fichtel Mountains caused floods in several rivers of Upper Franconia. On 14 January, the maximum discharge of $92.5 \mathrm{~m}^{3} \mathrm{~s}^{-1}$ was recorded at gauge Kauerndorf and $75.3 \mathrm{~m}^{3} \mathrm{~s}^{-1}$ at gauge Ködnitz. It was one of the biggest in terms of its magnitude and corresponded to a discharge of the 100-year return period at gauge Kauerndorf and the 10-year return period at gauge Ködnitz. Agricultural land and traffic routes were flooded, but no serious damage was reported. In Kulmbach, a dyke in the region of Burghaig was about to collapse due to the large volume of water. The water management authority opened the weir in Kulmbach, which prevented potential damages (Hof, 2011).

Water levels at eight sites during the winter flood of January 2011 were collected by the water management authority in Hof, Germany, in Kulmbach (see Fig. 1a). The water levels were measured using a levelling instrument $\mathrm{Ni} 2$ (Faig and Kahmen 2012). Based on the locations, the sites are categorized in four groups: sites 1,2, and 3 at the river White Main; site 4 at the Dobrach canal in the north; site 5 at a side canal; and sites 6,7, and 8 at the Mühl canal.

\section{$3.3 \quad$ 2-D HD model}

HEC-RAS 2-D was used as the 2-D hydrodynamic model to quantify uncertainties in the inundation. The model uses an implicit finite-difference solution algorithm to discretize time 


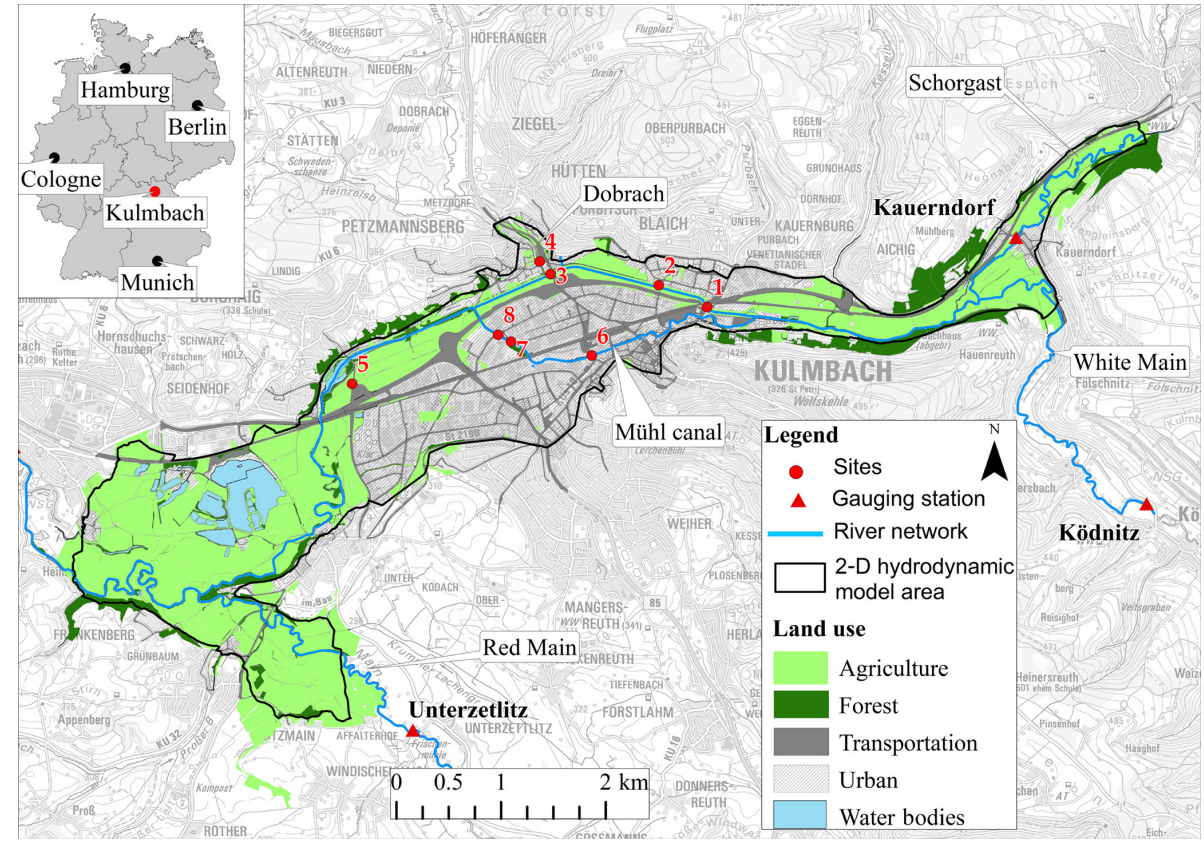

(a) Land use

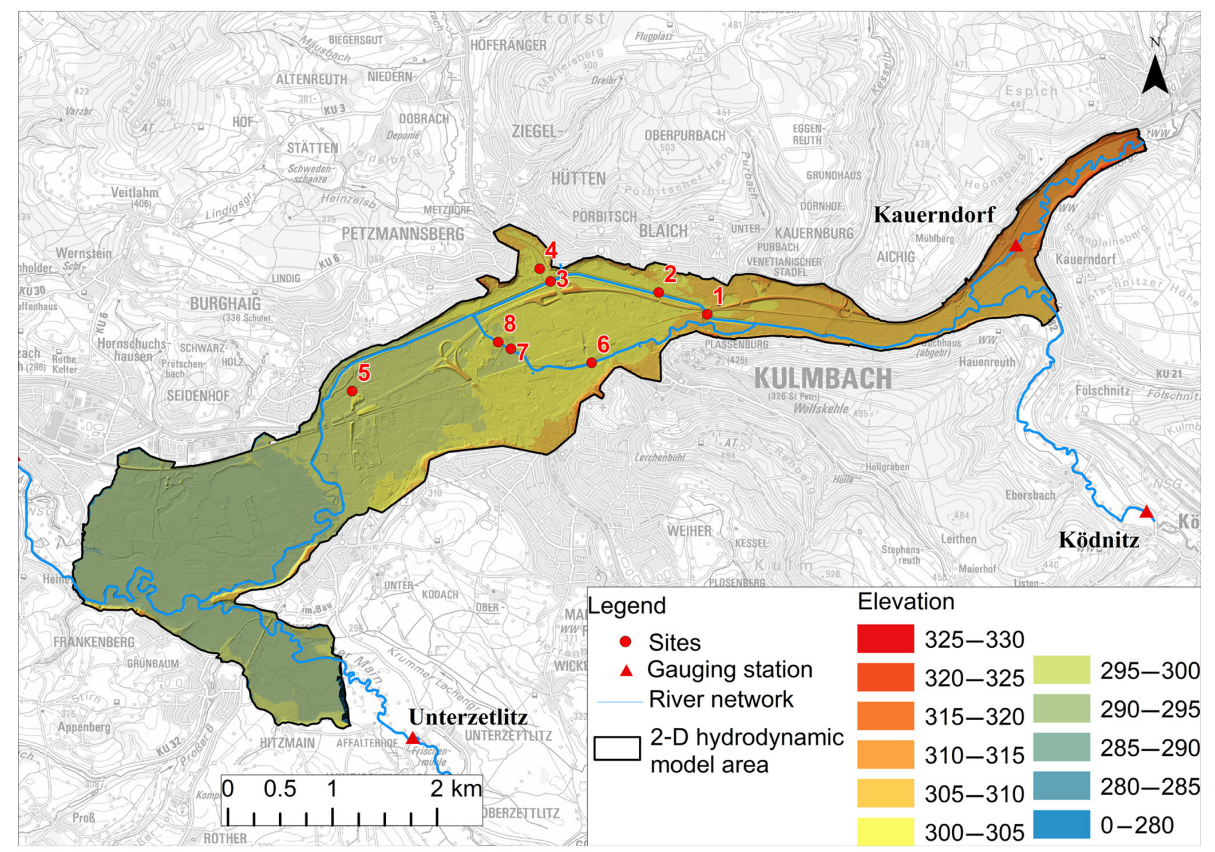

(b) Digital elevation model

Figure 1. Land use and the digital elevation model of the city of Kulmbach. Data source: Hof water management authority.

derivatives and hybrid approximations, combining finite differences and finite volumes to discretize spatial derivatives (Brunner, 2010). Table 2 shows the model properties and information of the cell size. We have used the unsteady diffusive wave model presented in previous work in Bhola et al. (2018a, b).

Measured discharge hydrographs described in the previous section were used as the upstream boundary condition at river gauges Ködnitz and Kauerndorf, and an energy slope value of 0.0096, based on the river slope, was used at the downstream boundary where the water flows out of the model domain. Along with the major rivers, canals were also represented as a discharge hydrograph type.

Digital elevation model for this study was provided by the Hof water management authority and presented in Fig. $1 b$. In the provided elevation model, the terrain is determined by 

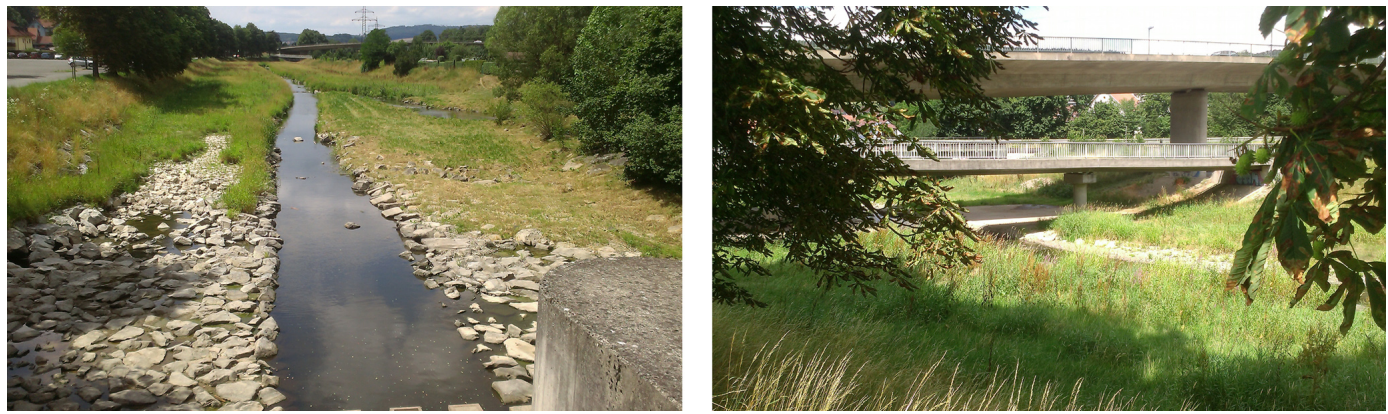

Figure 2. Main channel and flood plain of the river White Main near site 1 (image taken on 23 July 2015).

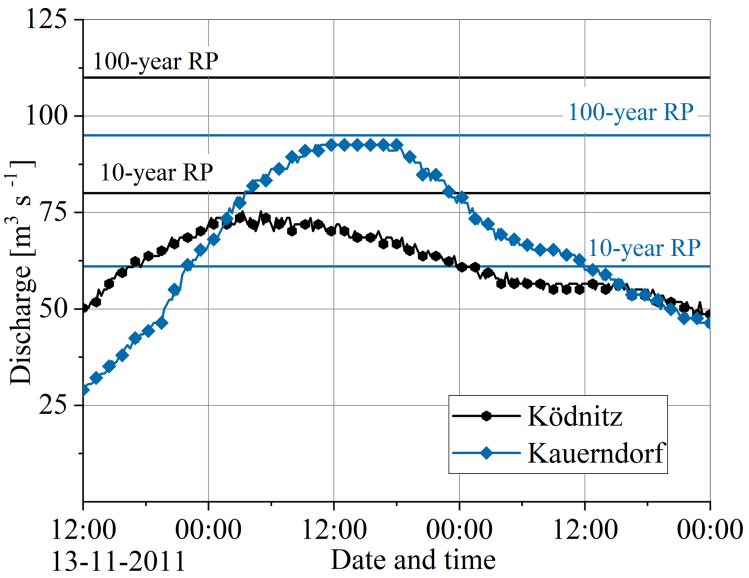

Figure 3. Discharge hydrographs at gauging stations upstream of the city, Ködnitz and Kauerndorf. RP stands for return period. Data source: Bavarian Hydrological Service (https://www.gkd.bayern. de/en/, last access: 27 March 2019).

Table 2. The 2-D hydrodynamic model properties.

\begin{tabular}{ll}
\hline Data & Value \\
\hline Model area & $11.5 \mathrm{~km}^{2}$ \\
Total number of cells & 430485 \\
$\Delta t$ & $20 \mathrm{~s}$ \\
Flood event duration & $42 \mathrm{~h}$ \\
Model run time & $5 \mathrm{~h}$ \\
Minimum cell area & $6.8 \mathrm{~m}^{2}$ \\
Maximum cell area & $59.8 \mathrm{~m}^{2}$ \\
Average cell area & $24.8 \mathrm{~m}^{2}$ \\
\hline
\end{tabular}

airborne laser scanning and airborne photogrammetry with a high resolution of $1 \mathrm{~m}$, whereas the riverbed was mostly recorded by the terrestrial survey. The combined elevation data were used to generate a triangulated irregular network (TIN) of the topography, which was then resampled to an irregular mesh of the 2-D HD model. Special attention was given in resampling in order to preserve important features, such as rivers, dykes, buildings, and roads.

\section{Results and discussion}

For the study, we have performed 1000 simulations based on uniformly distributed parameter sets for five land use classes. The sample size does contain enough samples of different behavioural models and the estimate was based on the recommendation in the literature (Aronica et al., 1998; Romanowicz and Beven, 2003) as well as the computational resources available. The HD models were simulated starting from 13 January 2011 00:00 central European summer time (time zone in Munich, GMT+2) to 14 January 2011 18:00 central European summer time (time zone in $\mathrm{Mu}-$ nich, GMT+2), which requires approximately $5 \mathrm{~h}$ to simulate an event of $42 \mathrm{~h}$ on an eight-core, Intel ${ }^{\circledR}$ Core $^{\mathrm{TM}} 2$ Duo CPU T7700 @ 2.40 cloud computer with 64 GB RAM. Eight cloud computers using the LRZ Compute Cloud, provided by the Leibniz Supercomputing Centre of the Bavarian Academy of Sciences and Humanities, were used to complete 1000 simulation in 2 weeks. Measured water levels at eight sites (see Sect. 3.2) were used for the analysis of the model output. The absolute error between the simulated and measured water level is used as the goodness of fit to reach the objective.

\subsection{Roughness range and distribution}

The model parameter consists of roughness coefficient Manning's $n$ for five land use classes. A simple model structure, such as diffusive wave approximation, does not represent the accurate values of roughness as this parameter is a scale-dependent effective value that compensates for varying conceptual errors in the model (Néelz et al., 2009). Hence, it is recommended to use feasible extreme upper and lower ranges for the parameters in the literature (Aronica et al., 1998; Bhola et al., 2018b). In this study, ranges of Manning's $n$ were set as $0.015-0.15$ for water bodies, which covers a range from very weedy reaches to rough asphalt; 0.025 0.110 for agriculture, short grass to medium-dense brush; $0.110-0.200$ for forests, dense trees (Chow, 1959); 0.0120.020 for transportation, firm soil to concrete; and 0.040 0.080 for parks to gravels in urban areas (Arcement and Schneider, 1989). Latin hypercube sampling was used to gen- 


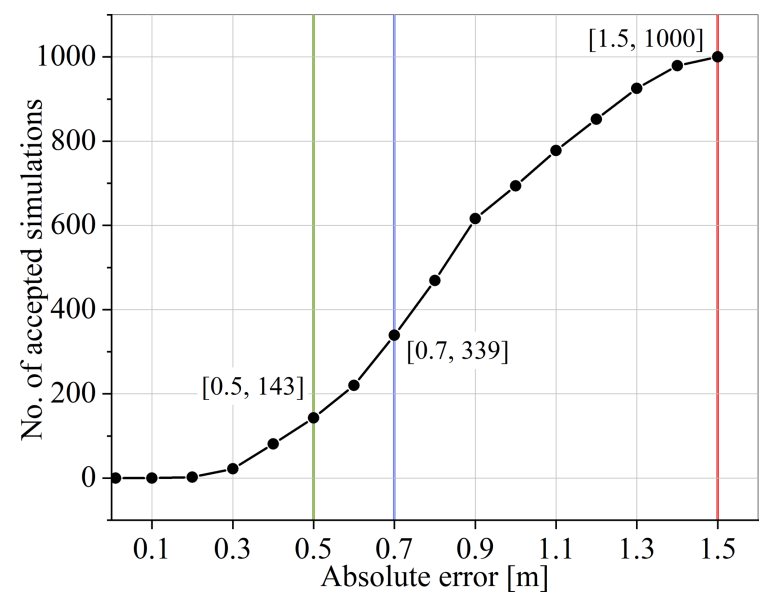

Figure 4. Accepted number of simulations vs. absolute error.

erate 1000 parameter sets using the upper and lower ranges of Manning's $n$ set as the prior and the HEC-RAS 2-D model was simulated for each set.

\subsection{Error tolerance}

For the analyses, the absolute error between the simulated and the measured water levels was calculated at eight sites. The simulations that produced an absolute error below a threshold at all the sites were selected. Figure 4 shows that as we increase the threshold, the number of accepted simulations increases. To find one calibrated parameter set, the least value of tolerance can be set at $0.20 \mathrm{~m}$ that gives two simulations that result in the least error at all sites. Having said that, the calibrated roughness set will probably hold true only for the January 2011 event as discussed in the study (Romanowicz and Beven, 2003). In order to generalize the results to other events and collect enough samples to produce uncertainty bounds, the tolerance needs to be increased. In this study, we have used $1.5,0.70$, and $0.50 \mathrm{~m}$ as the tolerance at sites to evaluate the roughness sensitivity, which results in 1000, 339, and 143 selected simulations respectively. Nevertheless, tolerance can be changed depending on the requirements of the user. To summarize, three thresholds are used to evaluate the performance of the method in order to reduce the uncertainty bounds and are termed as follows.

- Case I. Absolute error of $1.5 \mathrm{~m}$ resulting in 1000 simulations.

- Case II. Absolute error of $0.7 \mathrm{~m}$ resulting in 339 simulations.

- Case III. Absolute error of $0.5 \mathrm{~m}$ resulting in 143 simulations.
Table 3. Coefficient of determination $\left(R^{2}\right)$ between Manning's $n$ and absolute error for case I. The value above 0.18 are shown in italic.

\begin{tabular}{lrrrrr}
\hline \multirow{2}{*}{ Site } & \multicolumn{5}{c}{ Coefficient of determination $(-)$} \\
\cline { 2 - 6 } & $\begin{array}{r}\text { Water } \\
\text { bodies }\end{array}$ & Agriculture & Forest & $\begin{array}{r}\text { Transpor- } \\
\text { tation }\end{array}$ & Urban \\
\hline 1 & 0.04 & 0.89 & 0.00 & 0.00 & 0.00 \\
2 & 0.05 & 0.85 & 0.00 & 0.00 & 0.00 \\
3 & 0.18 & 0.69 & 0.00 & 0.00 & 0.00 \\
4 & 0.34 & 0.54 & 0.00 & 0.00 & 0.01 \\
5 & 0.45 & 0.37 & 0.00 & 0.00 & 0.00 \\
6 & 0.97 & 0.00 & 0.00 & 0.00 & 0.00 \\
7 & 0.23 & 0.18 & 0.00 & 0.00 & 0.00 \\
8 & 0.19 & 0.22 & 0.00 & 0.00 & 0.00 \\
\hline
\end{tabular}

\subsection{Roughness sensitivity}

The sensitivity of the model roughness was investigated, and it was observed that the sites were only sensitive to land use of water bodies and agriculture and no sensitivity was observed with respect to urban, transportation, and forest. Table 3 presents the coefficient of determination $\left(R^{2}\right)$ between Manning's $n$ for all the land uses and absolute error for case I. Site-specific dependency in Manning's $n$ and sites was observed for the cases in which the value of $R^{2}$ is found to be above 0.18 (in italic). The main reason for the lack of sensitivity can be explained by the location of the sites since they were mainly located next to bridges upstream from water bodies or agriculture land uses. Nonetheless, there are other influencing factors, such as the inundation area, velocity, and topography that could also play a role (Werner et al., 2005b). Figure 5 shows the maximum flood inundation map for the January 2011 flood event simulated using the optimal model parameters, which were obtained by the least absolute error of $0.20 \mathrm{~m}$. The inundation upstream to the sites is mainly constrained in the water bodies and agricultural land uses, which explains the impact on sensitivity of water levels to these two land uses.

The sensitivity to the land uses is apparent in the scatter plots between the absolute error and Manning's $n$ shown in Fig. 6. In the figure, it can be observed that cases II and III (with 339 and 143 accepted simulations) result in an absolute error of less than 0.70 and $0.50 \mathrm{~m}$ at the sites respectively. The selected simulations were further used in refining the uncertainty bounds. Sites 1, 2, and 3 (White Main) show a pattern with agriculture (flood plain): as Manning's $n$ increases, the error decreases until an optimal roughness is obtained and further increase in the roughness value results in an increased error. Sites 6, 7, and 8, located at the Mühl canal, show similar sensitivity towards water bodies. In the case of sites 4 and 5, sensitivity is observed for both land use types. The sensitivity found here is also reflected in other studies, 


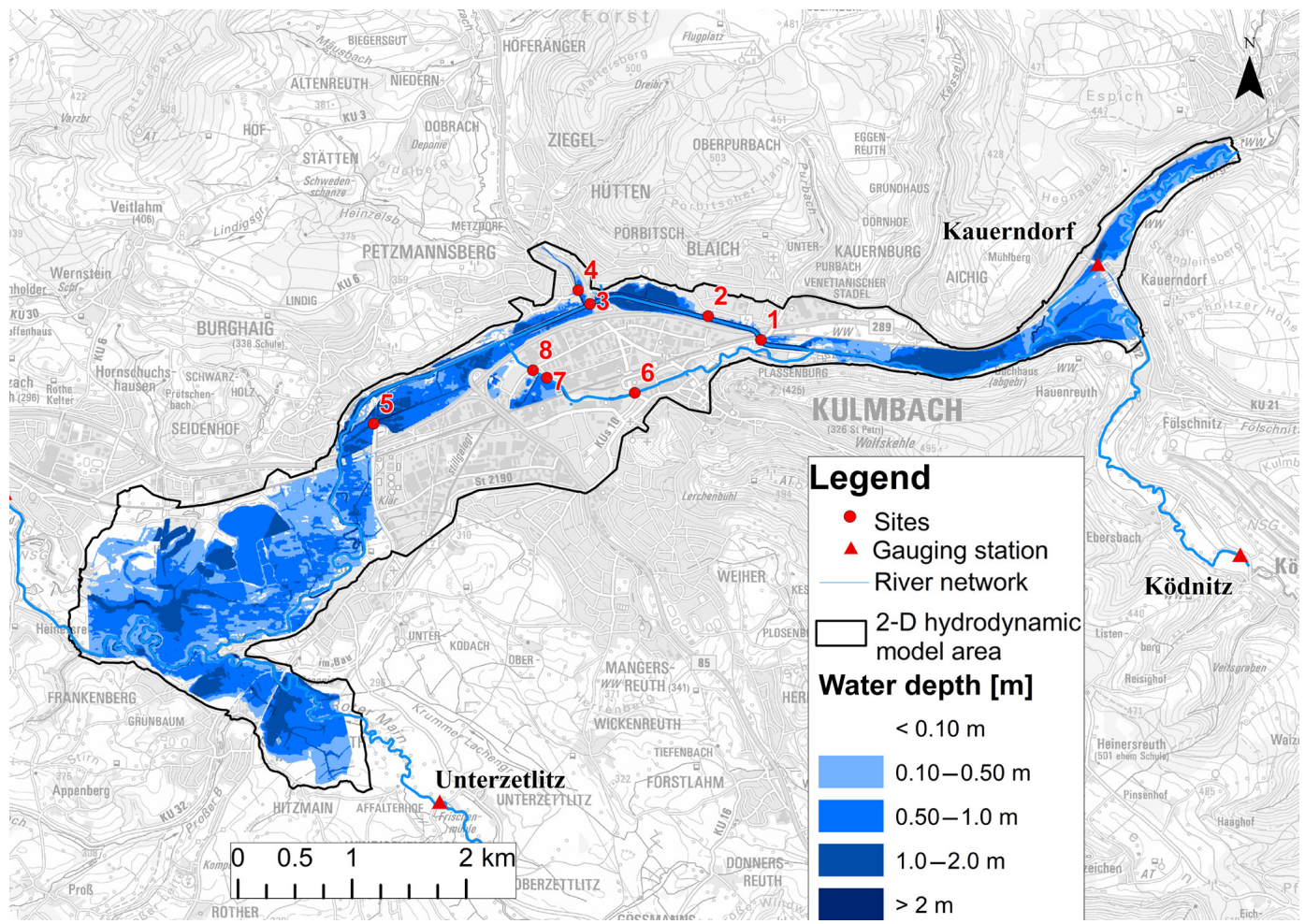

Figure 5. Inundation map for the flood event of January 2011 using the optimal model parameters, obtained using a least absolute error of $0.20 \mathrm{~m}$.

Table 4. The $90 \%$ confidence interval absolute error bounds $(\mathrm{m})$ for three cases along with measured water depth $(\mathrm{m})$ at eight sites for the January 2011 event.

\begin{tabular}{lrrrr}
\hline \multirow{2}{*}{ Site } & Measured & \multicolumn{3}{c}{$90 \%$ absolute error bounds } \\
\cline { 3 - 5 } & water depth & Case I & Case II & Case III \\
\hline 1 & 2.78 & 1.26 & 0.59 & 0.34 \\
2 & 2.90 & 1.04 & 0.55 & 0.34 \\
3 & 2.93 & 1.01 & 0.59 & 0.36 \\
4 & 1.43 & 0.97 & 0.64 & 0.46 \\
5 & 1.75 & 0.78 & 0.46 & 0.32 \\
6 & 0.89 & 0.85 & 0.65 & 0.43 \\
7 & 2.31 & 0.52 & 0.46 & 0.40 \\
8 & 2.36 & 0.51 & 0.46 & 0.40 \\
\hline
\end{tabular}

${ }^{1}$ Data source: water management authority in Hof, Germany.

such as sensitivity to flood plains (agriculture) (Aronica et al., 1998) and main channels (water bodies) (Hall et al., 2005), and insensitivity to other land uses for flood events (Horritt and Bates, 2002; Werner et al., 2005a).

\subsection{Uncertainty of water levels}

Table 4 shows the $90 \%$ confidence interval of the absolute error bounds of the simulated and measured water levels for three cases along with the measured available water depth. The impact of reducing the uncertainty is clear in the simulated flood inundation for the city of Kulmbach; the average uncertainty bound was $0.87 \mathrm{~m}$ and after constraining with the measured data, it was reduced to $0.55 \mathrm{~m}$ for case II and further reduced to 0.38 in case III. The maximum bound of $1.26 \mathrm{~m}$ was observed at site 1 , which was reduced to 0.59 and $0.34 \mathrm{~m}$ in cases II and III respectively. Sites 7 and 8 , located on the Mühl canal, showed the least effect of 0.12 and $0.11 \mathrm{~m}$ reduction in the bounds respectively (case III). Figure 7 presents a box plot of the difference in the simulated and measured water levels. The preselected literature values of Manning's $n$ tend to over-predict the water levels as the mean water level is well above zero at sites in case I. After constraining Manning's $n$, the mean drops considerably and is still above zero for all sites except 7 and 8 in both cases II and III. The figures also suggest that the simulations can both under- and over-predict the inundation, which might not be desired in some applications, such as early warning and evacuation planning. Furthermore, in situations where a few sites are more sensitive/important than others, a weighted goodness of fit can also be used. However, in this study, we have 


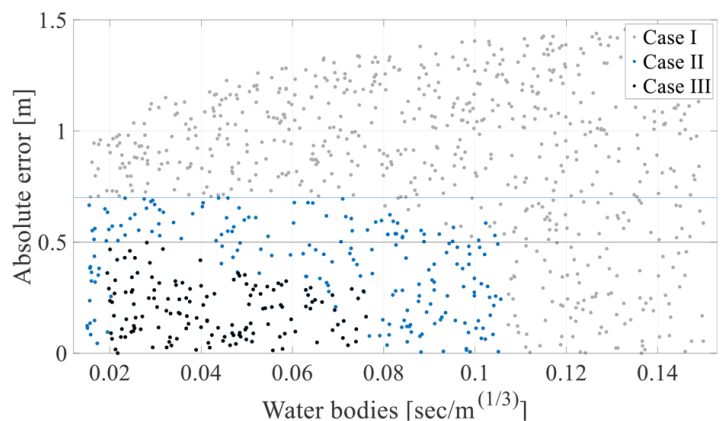

(a) Site 1: water bodies

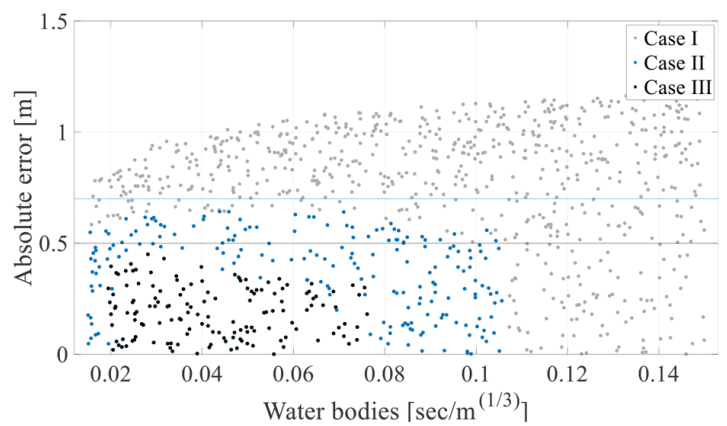

(c) Site 2: water bodies

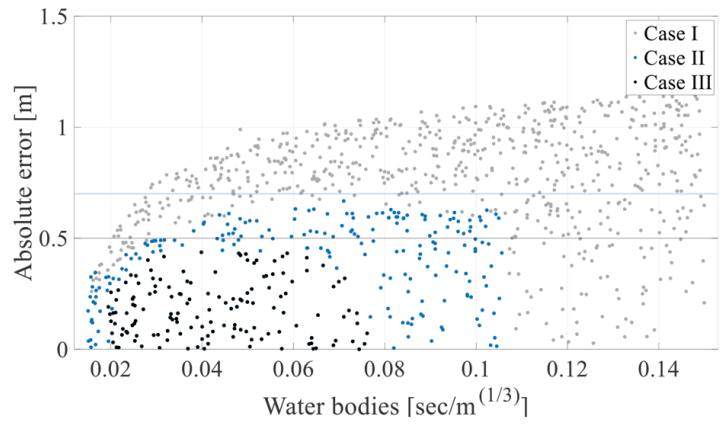

(e) Site 3: water bodies

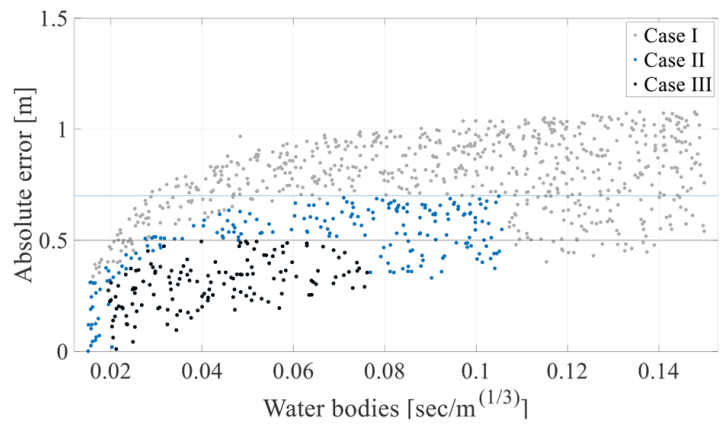

(g) Site 4: water bodies

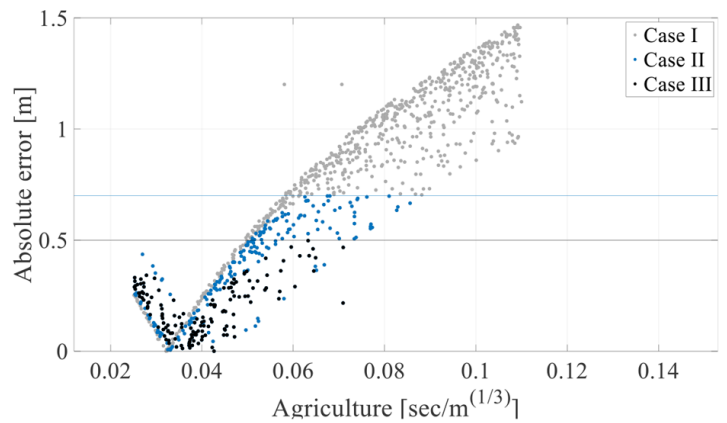

(b) Site 1: agriculture

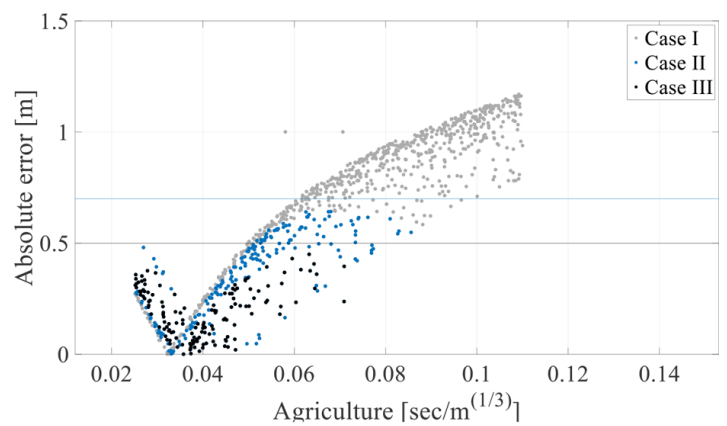

(d) Site 2: agriculture

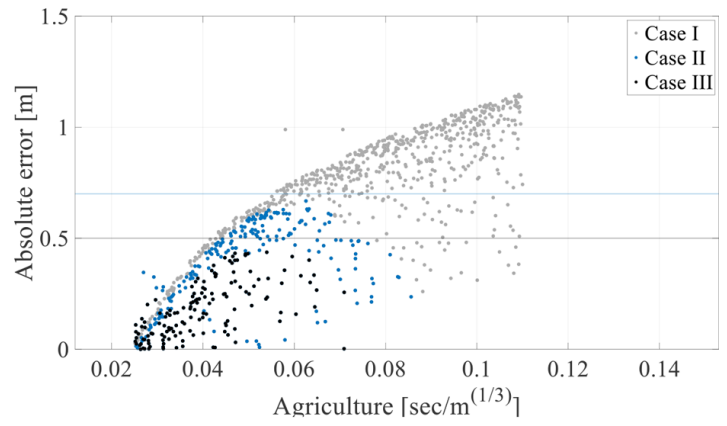

(f) Site 3: agriculture

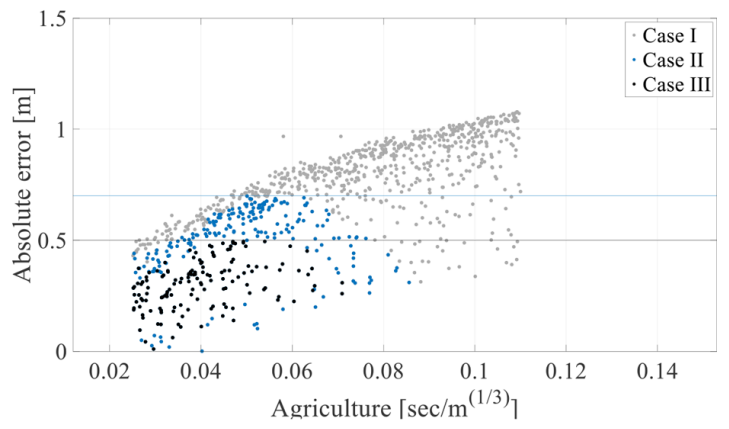

(h) Site 4: agriculture

Figure 6. Scatter plot of the absolute error of 1000 simulations in relation to water bodies and agriculture. Cases I, II, and III show accepted simulations based on threshold values of $1.5,0.7$, and $0.5 \mathrm{~m}$ respectively. 


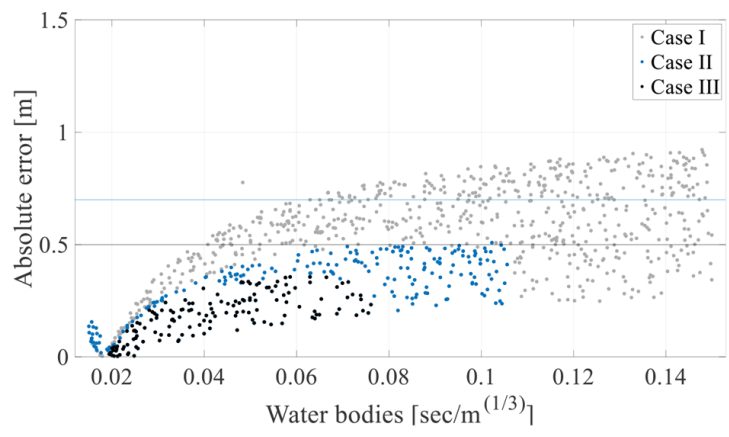

(i) Site 5: water bodies

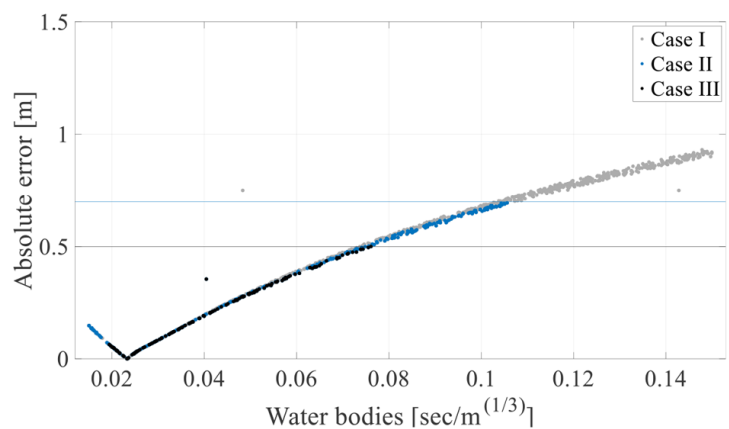

(k) Site 6: water bodies

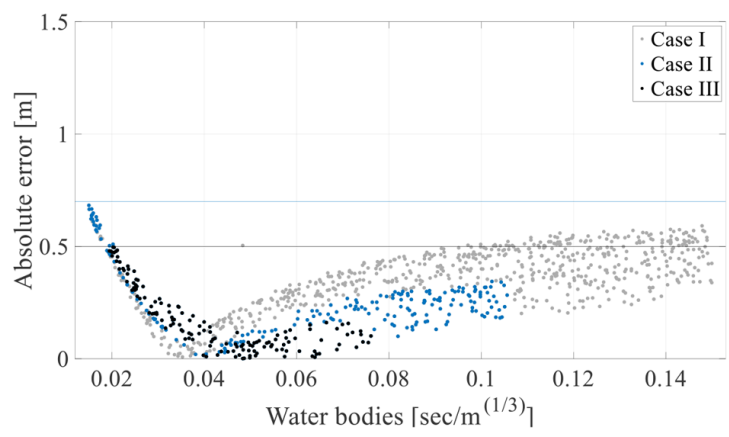

(m) Site 7: water bodies

Figure 6. Continued.

focused on the overall uncertainties, both positive and negative, for a comprehensive assessment.

\subsection{Constrained parameter set}

The main objective of this study was to reduce the uncertainty bounds of the model output by constraining the prior set for the roughness. In this section, it is shown that the literature-based prior used for Manning's $n$ can be reduced using measured water levels. Figure 8 presents the box plot of water bodies and agriculture roughness for three cases (1000, 339 , and 143 accepted simulations). As stated in the previous section, no sensitivity was observed between the sites and

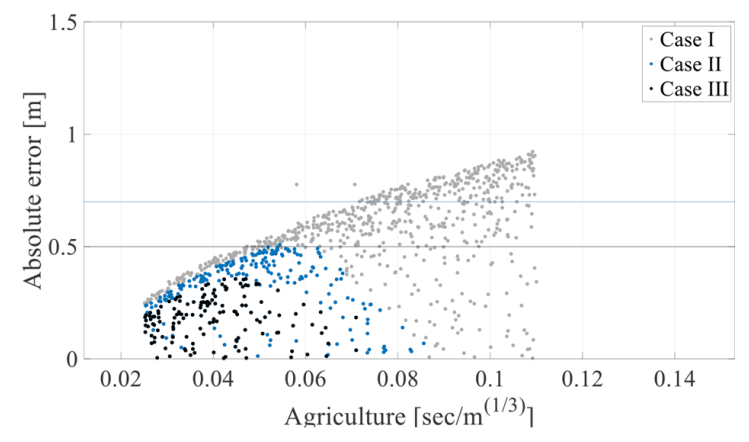

(j) Site 5: agriculture

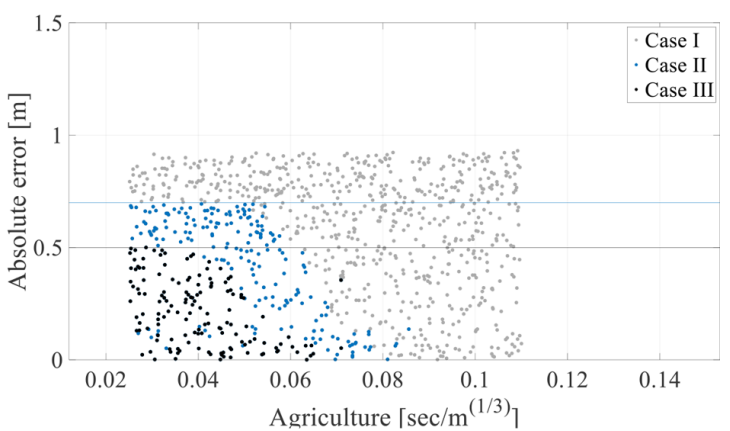

(l) Site 6: agriculture

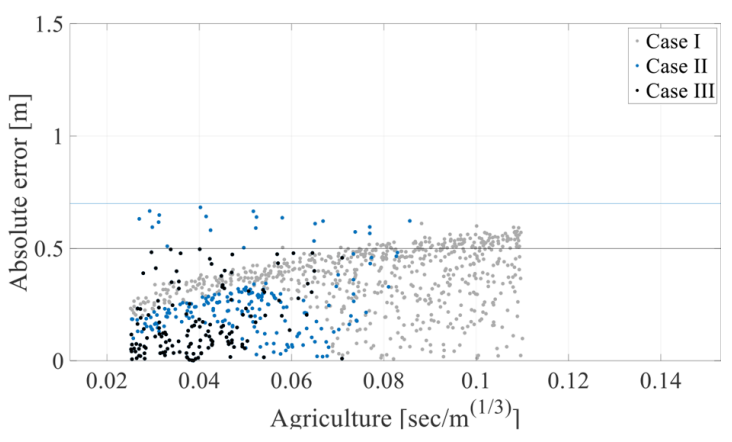

(n) Site 7: agriculture

other three land use types. Hence, the uncertainty bounds for other land use classes remain the same after the analysis.

In the case of water bodies, Manning's $n$ gradually concentrated in the range of $0.029-0.055$ ( $25 \%-75 \%$, case III). The physical interpretation of the constrained coefficient ranges in the main channels with stones to sluggish reaches (Chow, 1959). However, for agriculture, the mean dropped considerably from case I to case II and remains consistent in case III. The $25 \%-75 \%$ bounds of the coefficient were $0.032-0.047$ (case III) and can be interpreted as high grass to medium brush in the flood plains (Chow, 1959). This compares well to the results of Horritt and Bates (2002) in which they achieved an optimum in the range of 0.03-0.05 for the main channel 


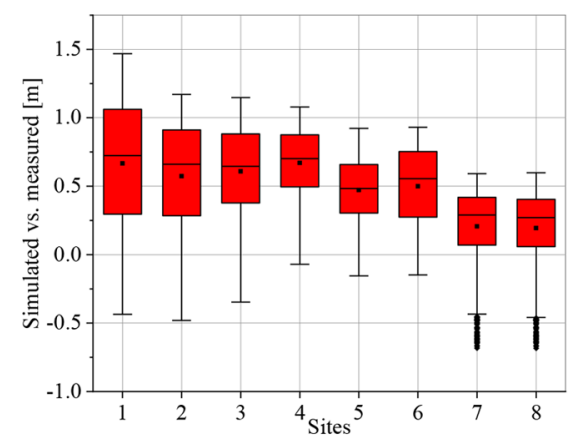

(a) Case I

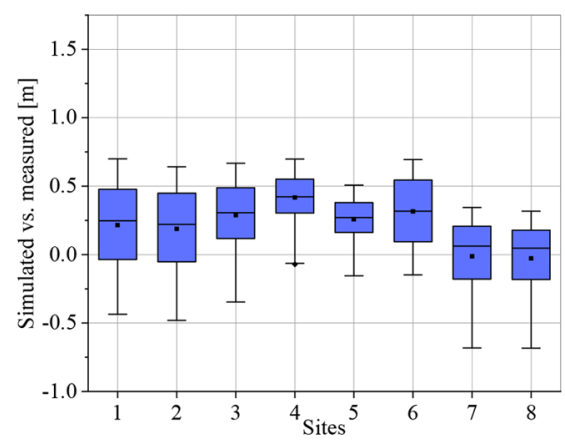

(b) Case II

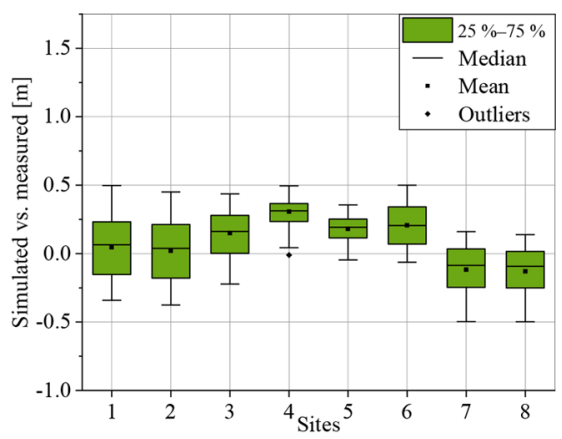

(c) Case III

Figure 7. Error in simulated vs. measured water levels for (a) case I, (b) case II, and (c) case III.

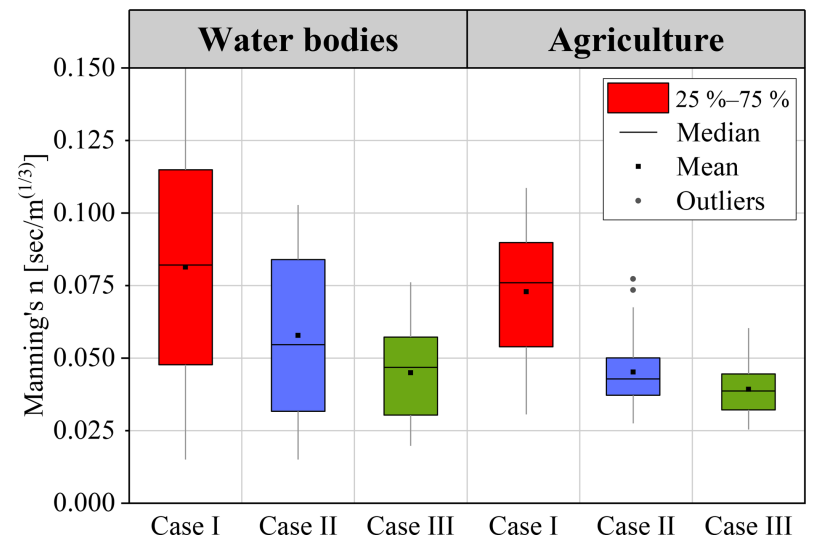

Figure 8. Box plot of Manning's $n$ of water bodies and agriculture for three cases.

and $0.02-0.10$ for the flood plain roughness of the 2-D HD models.

Both the main channel and flood plains are homogenous in the model area and the presence of stones and high grass is observed in the field (see Fig. 2). It was discussed previously in the Introduction, that the second modeller type believes that Manning's $n$ should be varied in a strictly known range based on field experiments. But these ranges can also be defined using a data-driven approach with the method presented. However, a detailed field experiment in the study area will be required to make a conclusive remark for a comparison between the field and evaluated coefficients. Furthermore, these ranges may vary for summer and winter events and various HD models can be built up depending on the season.

\section{Conclusions}

We have quantified the uncertainty associated with the model parameter for the flood event of January 2011 in the city of Kulmbach, Germany. Moreover, the study provides a com- prehensive review of HD model uncertainty and explores the issue of high uncertainty bounds, which hinder users from analysing uncertainties. We have provided a straightforward approach to practitioners for searching model parameter spaces for behavioural models and subsequently reduce the flood inundation uncertainty bounds. Extreme ranges of model roughness in the literature were selected and 1000 uniformly distributed models were run, which resulted in wide uncertainty bounds of up to $1.26 \mathrm{~m}(90 \%$ confidence interval). To reduce the bounds, measured water levels at eight sites were used and three cases were selected on the basis of absolute error threshold values of $1.5,0.7$, and $0.5 \mathrm{~m}$, which resulted in 1000, 343, and 143 accepted simulations respectively. By constraining the roughness, the bounds were reduced to a maximum of $0.34 \mathrm{~m}$. In addition, the model roughness was constrained, and the physical interpretation of the constrained roughness was discussed. The model roughness was spatially distributed based on five land uses and the model was sensitive only to water bodies and agriculture.

The method is easy to incorporate into other study areas, provided that there are measured water levels available. The uncertainty analysis presented in this study allows a better understanding of the model roughness variability in HD models. The ranges researched for Manning's $n$ in this study can represent a good starting point (prior distribution) for other studies. Our study has shown that there are significant uncertainties in HD model roughness and should be considered in decision-making. In addition, the study highlights the importance of field surveys for reducing the uncertainty in flood inundation outputs.

On an urban scale, the uncertainty assessment presented would substantially improve emergency responses by assessing the potential consequences of flood events (Molinari et al., 2014), and disaster relief organizations, such as the Federal Agency for Technical Relief (THW), the German Red Cross, and the Bavarian Water Authorities, would indeed benefit from prioritizing and coordinating evacuation planning. For advanced users such as decision makers in water management authorities, the uncertainty assessment should 
further serve as a tool for enhanced risk assessment. In addition, by visualizing inundation scenarios, improved flood mitigation and flood forecast planning strategies can be developed using a multi-model ensemble (Bhola et al., 2019) and potential damage can be estimated for various quantiles.

Under-prediction of a simulated inundation is not desired in most case studies; therefore, the goodness of fit used in this study could be a critical issue. Future work should include other evaluation measures to constrain the parameter ranges. As the high-computational resources hinder a comprehensive uncertainty assessment of a full dynamic HD model, it is worth exploring transferability of the evaluated uncertainty bounds of Manning's $n$ of the simple model structure (diffusive wave) to a complex model structure. Furthermore, other sources of uncertainty, such as model input (hydrological model in Disse et al., 2018), discharge measurement error, or flood frequency estimations, and digital elevation map and measured water level, which is assumed to have no error, should also be incorporated for a comprehensive assessment. The parameter ranges were constrained based on a single event in this study; however, the values can be further validated using another flood event of higher magnitude. Land use in this study is divided into five classes; in future, further reclassification of land use, especially in urban areas, will help further reduce the bounds (Bhola et al., 2018c).

The inundation model should be extended to simulate urban pluvial flooding in future by including a 1-D-2-D sewer/overland flow coupled-model structure (Leandro et al., 2011). This will bring other sources of uncertainties as there are numerous uncertain parameters associated with this model structure (Djordjević et al., 2014). With an everincreasing computational performance and the introduction of cloud computing, the integration of more complex models will become feasible.

Data availability. Data from this research are not publicly available. Interested researchers can contact the corresponding author of this article.

Author contributions. The study was conceptualized by PKB and $\mathrm{MD}$; PKB conceptualized and completed the formal analysis of uncertainty analysis. PKB wrote the original draft, which was subsequently reviewed and edited by all co-authors. All authors contributed to writing the paper.

Competing interests. The authors declare that they have no conflict of interest.

Acknowledgements. This research was funded by the German Federal Ministry of Education and Research (BMBF). In addition, this work was supported by the German Research Foundation (DFG) and the Technical University of Munich (TUM) in the framework of the Open Access Publishing Fund. The authors would like to thank all contributing project partners, funding agencies, politicians, and stakeholders in different functions in Germany. A very special thanks to the Bavarian Water Authority and Bavarian Environment Agency in Hof for providing us with the quality data to conduct the research. We would also like to thank the language centre of the Technical University of Munich for their consulting in English writing.

Financial support. This research has been supported by the Bundesministerium für Bildung und Forschung (grant no. FKZ 13N13196).

This work was supported by the German Research Foundation (DFG) and the Technical University of Munich (TUM) in the framework of the Open Access Publishing Fund.

Review statement. This paper was edited by Mario Parise and reviewed by Guy J.-P. Schumann and one anonymous referee.

\section{References}

Arcement, G. J. and Schneider, V. R.: Guide for selecting manning's roughness coefficients for natural channels and flood plains, Water-Supply paper 2339, United States Department of Transportation, Denver, USA, 38 pp., 1989.

Aronica, G., Hankin, B., and Beven, K.: Uncertainty and equifinality in calibrating distributed roughness coefficients in a flood propagation model with limited data, Adv. Water Resour., 22, 349-365, https://doi.org/10.1016/S0309-1708(98)00017-7, 1998.

Bach, P. M., Rauch, W., Mikkelsen, P. S., McCarthy, D. T., and Deletic, A.: A critical review of integrated urban water modelling - urban drainage and beyond, Environ. Modell. Softw., 54, 88107, https://doi.org/10.1016/j.envsoft.2013.12.018, 2014.

Bales, J. D. and Wagner, C. R.: Sources of Uncertainty in flood inundation maps, J. Flood Risk Manag., 2, 139-147, https://doi.org/10.1111/j.1753-318X.2009.01029.x, 2009.

Bates, P. D., Pappenberger, F., and Romanowicz, R. J.: Uncertainty in flood inundation modelling, in: Applied uncertainty analysis for flood risk management, edited by: Beven, $\mathrm{K}$. and Hall, J., Imperial College Press, London, UK, 232-269, https://doi.org/10.1142/9781848162716_0010, 2014.

Beven, K.: A manifesto for the equifinality thesis, J. Hydrol., 320, 18-36, https://doi.org/10.1016/j.jhydrol.2005.07.007, 2006.

Beven, K. J., Almeida, S., Aspinall, W. P., Bates, P. D., Blazkova, S., Borgomeo, E., Freer, J., Goda, K., Hall, J. W., Phillips, J. C., Simpson, M., Smith, P. J., Stephenson, D. B., Wagener, T., Watson, M., and Wilkins, K. L.: Epistemic uncertainties and natural hazard risk assessment - Part 1: A review of different natural hazard areas, Nat. Hazards Earth Syst. Sci., 18, 2741-2768, https://doi.org/10.5194/nhess-18-2741-2018, 2018.

Bhola, P. K., Bhavna, N., Leandro, J., Rao, S. N., and Disse, M.: Flood inundation forecasts using validation data generated with the assistance of computer vision, J. Hydroinform., 21, 240-256, https://doi.org/10.2166/hydro.2018.044, 2018a. 
Bhola, P. K., Leandro, J., and Disse, M.: Framework for offline flood inundation forecasts for twodimensional hydrodynamic models, Geosciences, 8, 346, https://doi.org/10.3390/geosciences8090346, 2018 b.

Bhola, P. K, Ginting, B. M., Leandro, J., Broich, K., Mundani, R. P., and Disse, M.: Model parameter uncertainty of a 2-D hydrodynamic model for the assessment of disaster resilience, EnviroInfo, Garching, Munich, 5-7 September 2018, 2018 c.

Bhola, P. K., Leandro, J., and Disse, M.: Hazard maps with differentiated exceedance probability for flood impact assessment, Nat. Hazards Earth Syst. Sci. Discuss., https://doi.org/10.5194/nhess2019-158, in review, 2019.

Brunner, G. W.: HEC-RAS River Analysis System Hydraulic Reference Manual, Report for US Army Corps of Engineers, Hydrologic Engineering Center (HEC), Davis, CA, USA, 547 pp., 2010.

Chow, V. T.: Development of uniform flow and its formulas, in: Open-channel hydraulics, McGraw-Hill Book Company, edited by: Harmer, D. E., USA, 89-114, 1959.

Disse, M., Konnerth, I., Bhola, P. K., and Leandro, J.: Unsicherheitsabschätzung für die Berechnung von Dynamischen Überschwemmungskarten - Fallstudie Kulmbach, in: Vorsorgender und nachsorgender Hochwasserschutz, edited by: Heimerl, S., Springer Vieweg, Wiesbaden, Germany, 350-357, https://doi.org/10.1007/978-3-658-21839-3_50, 2018.

Djordjević, S., Vojinović, Z., Dawson, R., and Savić, D. A.: Uncertainties in flood modelling in urban areas, in: Applied uncertainty analysis for flood risk management, edited by: Beven, K. and Hall, J., Imperial College Press, London, UK, 297-334, https://doi.org/10.1142/9781848162716_0012, 2014.

Faig, W. and Kahmen, H.: Differential levelling, in: Surveying, edited by: Kahmen, H. and Faig, W., De Gruyter, Berlin, Germany, 321-386, 2012.

Hagemeier-Klose, M.: Results of formative evaluation of information tools in flood risk communication, final report on formative evaluation - EU-Life project FloodScan, Technical University of Munich, Germany, 14 pp., 2007.

Hall, J. W., Tarantola, S., Bates, P. D., and Horritt, M. S.: Distributed sensitivity analysis of flood inundation model calibration, J. Hyd. Eng., 131, 117-126, https://doi.org/10.1061/(ASCE)07339429(2005)131:2(117), 2005.

Henonin, J., Russo, B., Mark, O., and Gourbesville, P.: Real-time Urban Flood Forecasting and Modelling A State of the Art, J. Hydroinform., 15, 717-736, https://doi.org/10.2166/hydro.2013.132, 2013.

Hof: Gebiet des Mains: available at: https://www.wwa-ho.bayern. de/hochwasser/hochwasserereignisse/januar2011/main/index. htm, last access: 27 March 2019, 2011.

Horritt, M. S. and Bates, P. D.: Evaluation of 1-D and 2-D numerical models for predicting river flood inundation, J. Hydrol., 268, 8799, https://doi.org/10.1016/S0022-1694(02)00121-X, 2002.

Hunter, N. M., Bates, P. D., Horritt, M. S., and Wilson, M. D.: Simple spatially-distributed models for predicting flood inundation: A review, Geomorphology, 90, 208-225, https://doi.org/10.1016/j.geomorph.2006.10.021, 2007.

Jung, Y. and Merwade, V.: Uncertainty quantification in flood inundation mapping using generalized likelihood uncertainty estimate and sensitivity analysis, J. Hydrol. Eng., 17, 507-520, https://doi.org/10.1061/(ASCE)HE.1943-5584.0000476, 2012.
Leandro, J., Djordjević, S., Chen, A. S., Savić, D. A., and Stanić, M.: Calibration of a 1-D/1-D urban flood model using 1-D/2-D model results in the absence of field data, J. Water Sci. Tech., 64, 1016-1024, https://doi.org/10.2166/wst.2011.467, 2011.

Matott, L. S., Babendreier, J. E., and Purucker, S. T.: Evaluating uncertainty in integrated environmental models: A review of concepts and tools, Water Resour. Res., 45, W06421, 1-14, https://doi.org/10.1029/2008WR007301, 2009.

Merwade, V., Olivera, F., Arabi, M., and Edleman, S.: Uncertainty in flood inundation mapping: Current issues and future directions, J. Hydrol. Eng., 13, 608-620, https://doi.org/10.1061/(ASCE)1084-0699(2008)13:7(608), 2008.

Molinari, D., Ballio, F., Handmer, J., and Menoni, S.: On the modeling of significance for flood damage assessment, Int. J. Disaster Risk Reduct., 10, 381-391, https://doi.org/10.1016/j.ijdrr.2014.10.009, 2014.

Musall, M., Oberle, P., and Nestmann, F.: Hydraulic modelling, in: Flood risk assessment and management: How to specify hydrological loads, their consequences and uncertainties, edited by: Schumann, A. H., Springer, Dordrecht, Netherlands, 187-209, https://doi.org/10.1007/978-90-481-9917-4_9, 2011.

Néelz, S. and Pender, G.: Desktop review of 2D hydraulic modelling packages, Science Report SC080035, Joint UK Defra/Environment Agency Flood and Coastal Erosion, Risk Management R\&D Program, 63 pp., 2009.

Oubennaceur, K., Chokmani, K., Nastev, M., Tanguy, M., and Raymond, S.: Uncertainty analysis of a two-dimensional hydraulic model, Water, 10, 272, https://doi.org/10.3390/w10030272, 2018.

Pappenberger, F. and Beven, K. J.: Ignorance is bliss: 7 reasons not to use uncertainty analysis, Water Resour. Res., 42, W05302, https://doi.org/10.1029/2005WR004820, 2006.

Pappenberger, F., Beven, K., Horritt, M., and Blazkova, S.: Uncertainty in the calibration of effective roughness parameters in hecras using inundation and downstream level observations, J. Hydrol., 302, 46-69, https://doi.org/10.1016/j.jhydrol.2004.06.036, 2005.

Romanowicz, R. and Beven, K.: Estimation of flood inundation probabilities as conditioned on event inundation maps, Water Resour. Res., 39, 3, https://doi.org/10.1029/2001WR001056, 2003.

Schumann, A. H., Wang, Y., and Dietrich, J.: Framing uncertainties in flood forecasting with ensembles, in: Flood risk assessment and management: How to specify hydrological loads, their consequences and uncertainties, edited by: Schumann, A. H., Springer, Dordrecht, Netherlands, 53-76, https://doi.org/10.1007/978-90-481-9917-4_4, 2011.

Thieken, A. H., Kienzler, S., Kreibich, H., Kuhlicke, C., Kunz, M., Mühr, B., Müller, M., Otto, A., Petrow, T., Pisi, S., and Schröter, K.: Review of the flood risk management system in Germany after the major flood in 2013, Ecol. Soc., 21, 1-12, https://doi.org/10.5751/ES-08547-210251, 2016.

Uusitalo, L., Lehikoinen, A., Helle, I., and Myrberg, K.: An overview of methods to evaluate uncertainty of deterministic models in decision support, Environ. Modell. Softw., 63, 24-31, https://doi.org/10.1016/j.envsoft.2014.09.017, 2015.

Wagener, T. and Gupta, H. V.: Model identification for hydrological forecasting under uncertainty, Environ. Res. Ris. Assess., 19, 378-387, https://doi.org/10.1007/s00477-005-0006-5, 2005. 
Werner, M., Blazkova, S., and Petr, J.: Spatially distributed observations in constraining inundation modelling uncertainties, Hydrol. Process., 19, 3081-3096, https://doi.org/10.1002/hyp.5833, 2005a.
Werner, M. G. F., Hunter, N. M., and Bates, P. D.: Identifiability of distributed floodplain roughness values in flood extent estimation, J. Hydrol., 314, 139-157, https://doi.org/10.1016/j.jhydrol.2005.03.012, 2005 b. 